\title{
Study on Gastrointestinal Parasitism of Wild Animals in Captivity at the Zoological Garden of Haramaya University, Ethiopia
}

\author{
Dakalo Dashe ${ }^{1 *}$, Amare Berhanu² \\ ${ }^{1}$ College of Veterinary Medicine, Haramaya University, Dire Dawa, Ethiopia \\ ${ }^{2}$ Department of Food and Animal Sciences, Alabama A\&M University, Normal, Alabama, USA \\ Email: *dfdaki@gmail.com
}

How to cite this paper: Dashe, D. and Berhanu, A. (2020) Study on Gastrointestinal Parasitism of Wild Animals in Captivity at the Zoological Garden of Haramaya University, Ethiopia. Open Journal of Veterinary Medicine, 10, 173-184.

https://doi.org/10.4236/ojvm.2020.109015

Received: August 28, 2020

Accepted: September 19, 2020

Published: September 22, 2020

Copyright () 2020 by author(s) and Scientific Research Publishing Inc. This work is licensed under the Creative Commons Attribution International License (CC BY 4.0).

http://creativecommons.org/licenses/by/4.0/

\begin{abstract}
Captivity of wild animals and restriction of their movement can lead to stress, resulting in suppressed immune response and reduced disease resistance ability. Wild animals in zoological gardens can predominately affected by various gastro-intestinal parasites. This study was therefore, conducted to determine occurrence, identify types and assess seasonal variation of gastrointestinal parasites in captive animals at the Zoological garden of Haramaya University. The study involved a retrospective investigation of zoo records and fecal examinations. Twenty two fecal samples were collected in December, 2013 from all the animals in the garden and examined using concentration and fecal culture techniques. Sampling was repeated after four months in April, 2014 to assess seasonal variations of the parasites. The result from the retrospective study showed death of 21 animals in the last five years. Fecal examination confirmed presence of gastrointestinal parasites with an overall mean prevalence rate of $73.8 \%$. A total of 9 parasite taxa were identified of which 6 (66.67\%) and $4(33.33 \%)$ were helminths and protozoa respectively. No Cestode and Trematode species were recovered. Trichuris spp., Toxocara spp., Strongyloides spp., Toxascaris leonine, Passalurus ambiguous and Ascaridia spp. were the helminth parasites observed in the garden. Entamoeba spp., Isospora spp. and Eimeria spp. were the protozoan parasites encountered. No remarkable seasonal variation in parasitic infection was noticed in the garden. The study revealed occurrence of gastrointestinal parasites in the zoological garden, most of which are zoonotic and hence future studies are needed to determine risks of cross-transmission.
\end{abstract}

\section{Keywords}

Gastrointestinal Parasite, Captive Wild Animals, Zoological Garden 


\section{Introduction}

Large populations of wild animals in captivity are affected by various diseases. Parasite infections are one of the major problems in the wild animals in captivity. Gastrointestinal parasites are frequently reported to affect the health and the wellbeing of the animals in zoological gardens [1]. The species of the gastrointestinal parasites infecting wild animals in captivity might differ with the type of animals and the management practices [2] [3].

In captivity, animals appear to be less resistant to parasitic infections than under their natural habitats [4]. The changes in environment and living conditions from the natural habitat to captivity alter the life styles of animals, reduce disease resistance ability and increase their susceptibility to parasitic infections [5] [6] [7]. Vulnerability of captive wild animals to parasitic infections depends on factors, like feeding, keeping conditions, animal management and environmental conditions, such as temperature and humidity. Confining captive animals in cages accompanied with improper feeding systems and poor sanitation may lead to contamination of environment, which makes the animals more prone to different parasitic infections [4] [6] [8] [9]. Proximity and close contact of humans with captive animals provide opportunity for the transmission of new parasite species which would not normally come in contact with them in the natural habitat [10]. Most of the deaths of wild animals in controlled areas are amounted to parasitic diseases. Parasitism, especially endoparasitic infection produces ill effects like weakness, emaciation, inappetance in zoo animals that can cause immune suppression and potentially predispose the animals to other diseases [11].

Although many parasitological investigations are conducted in domestic animals for long period of time, it has been recently recognized that parasitic infections are also common and important in wild animals [12] [13]. Incidence of gastrointestinal parasites in wild and zoo animals has been reported from different parts of the world [9] [14]. Several studies have been carried out on gastro-intestinal parasites in non-human primates [15] [16] [17] [18] [19], wild carnivores [20] [21] [22], wild herbivore animals [6] [7] [23], birds in captivity [11] [24] [25] [26], reptiles [27] and many other zoo animals across the globe.

Haramaya University zoological garden was established in 1966 for conservation of wild animals, recreational purpose, wild life education and research (Beadles and Ingersol, 1968, Haile Sellassie I University (HSIU) Experiment station Publication). Up on foundation, the garden started conservation with a total of 129 animals representing 51 different species. However, most of the species of animals that the garden started conservation with do not exist today. The number of species in the garden has been gradually reduced to 9 , consisting of a total of 25 animals. Lions (Panthera leo), Hamadryas baboon (Papio hamadryas), Vervet monkey (Cercopithecus aethiops), Lesser kudu (Tragelaphus imberbis), Spotted hyena (Crocuta crocuta), Kit foxes (Vulpes macrotis), Japanese rabbit (Oryctolagus cuniculus), Helmeted guinea fowl (Numida meleagris) and East 
African Giant Tortoise (Geochelone sulcata) are the species of wild animals currently found at the zoological garden.

There are incidences that the health problems and death of the zoo animals is usually connected with infection of gastrointestinal parasites. However, the attention given to investigate and document the type of gastrointestinal parasites infecting zoo animals in the country in general and at Haramaya University in particular is minimal. This study was therefore conducted to determine the occurrence, identify species and assess seasonal variation of gastrointestinal parasites in captive animals at the Zoological garden of Haramaya University.

\section{Materials and Methods}

\subsection{Description of the Study Area}

The study was conducted at the Zoological garden of Haramaya University, $9^{\circ} 26^{\prime} \mathrm{N}$ latitude and $42^{\circ} 03^{\prime} \mathrm{E}$ longitude at an altitude of 1980 m.a.s.l., $520 \mathrm{~km}$ east of the capital, Addis Ababa. The area has three common seasons; the two rain periods and one dry period. The rain seasons are from June to September ( Kiremt rains) and February to May (Belg rains) while the dry period extends from October to January (Bega season). The mean annual rainfall is $780 \mathrm{~mm}$ with average minimum and maximum temperatures of $8.25^{\circ} \mathrm{C}$ and $23.4^{\circ} \mathrm{C}$, respectively. In the garden, animals are housed in different cages individually and/or in small groups based on species and age of the animals.

\subsection{Study Methodology}

The study involved observation of the general management practices and retrospective investigation of zoo records, detection and identification of the parasites infecting the animals at the zoological garden. Fecal samples were analyzed for the presence and identification of nematodes, cestodes and protozoan oocysts. Samples from the East African Giant Tortoise (Geochelone sulcata) were excluded due to the failure to obtain fresh samples.

\subsection{Fecal Sample Collection}

Twenty two fresh fecal samples were collected from eight species, consisting of 22 zoo animals two times in December 2013 by using a sterile spatula. The samples were grossly examined immediately for the presence of adult worms and their larva and then placed into labeled sterile screw cap plastic containers for other parasitological techniques. Sampling was repeated in the same way after four months in April 2014 to assess seasonal variations of the parasites and samples were analyzed at parasitology laboratory of School of Animal and Range Sciences, Haramaya University. Only twenty animals were examined in April due death of two animals during the project work.

\subsection{Identification of Parasite Oocyst}

Zinc sulphate centrifugal floatation technique was used for the identification of 
nematode and protozoan eggs. About $3 \mathrm{gm}$ of fecal sample was mixed with $15 \mathrm{ml}$ of $\mathrm{ZnSO}_{4}$ solution and the resulting solution was strained through a nylon tea strainer to remove coarse fecal material. The solution was poured into a centrifuge tube and centrifuged at $2000 \mathrm{rpm}$ for 5 minutes. The tubes were removed from the centrifuge and filled with the flotation solution to the top; and then cover slips were placed over the top of the tube and left for 10 minutes. Finally, a drop of iodine solution was put on each slide and covered with cover slide and examined under microscope at $40 \mathrm{X}$ objective. Identification of helminths and protozoan oocysts were done by standard parasitological criteria [28] [29].

On the other hand fecal sedimentation technique was used for the examination of eggs of trematodes and cestodes. A small quantity of faeces ( $3 \mathrm{gm}$ ) was mixed well with water $(15 \mathrm{ml})$ and the resulting emulsion was strained through a nylon tea strainer to remove coarse faecal material. The filtrate was poured into a centrifuge tube and centrifuged at $2000 \mathrm{rpm}$ for 5 minutes. The supernatant was discarded and the tube was refilled with water and centrifuged $2-3$ occasions until clear supernatant was observed. Then a drop of the sediment was taken on a clean, dry glass slide and examined under low power (10X) of the microscope. Identification of the helminth eggs were carried out by standard parasitological procedures [28] [29] [30].

\subsection{Parasite Larval Identification}

About $10 \mathrm{gm}$ of fecal samples were collected for coproculture examination. The samples were broken up in a Petri dish and mixed with vermiculite and distilled water to form a homogenous wet mixture. The dishes were closed and placed in an incubator for 14 days. The larvae were then recovered by a Baermann apparatus where the samples were placed in double layer of gauze and suspended in a spring clipped funnel containing tape water. The fecal cultures were left to stand on the bench at ambient temperature for 24 hours. Approximately $15 \mathrm{ml}$ of the fluids were taken into tubes by releasing the spring clip; the tubes were put in refrigerator for 3 hours. The supernatants were removed leaving about $1 \mathrm{ml}$ of the sediment in the tube. The larvae in the sediment were transferred to microscope slides and examined. The identification keys described in Soulsby [28] and van Wyk and Mayhew [31] were employed to identify the larvae.

\section{Results and Discussion}

The data from retrospective study indicated that most of the disease cases of wild animals at Zoological garden of Haramaya University were related to parasite infections. Records revealed the death of 21 animals over the last five years (Table 1). The death for the animals might be due to gastrointestinal parasites accompanied with poor management practices and poor nutrition. Previous studies on feeding and management of zoo animals reported that the poor nutritional status and poor management practices can diminish resistance to parasitic disease [21] [32] [33]. 
Table 1. Number of wild animals died from 2008-2012.

\begin{tabular}{|c|c|c|c|c|c|c|}
\hline \multirow{2}{*}{ Species of Animals died } & \multicolumn{5}{|c|}{ Number of animals died } & \multirow{2}{*}{ Tota } \\
\hline & 2008 & 2009 & 2010 & 2011 & 2012 & \\
\hline Vervet monkey (Cercopithecus aethiops) & & 1 & & & & 1 \\
\hline Grey Duiker (Sylvicapra grimmia Abyssinia) & 1 & 3 & & & 1 & 4 \\
\hline Ethiopian Hare (Lepus aethiops) & 1 & & 1 & & 2 & 4 \\
\hline Civet (Civettictis Civetta) & & 1 & & & & 1 \\
\hline Helmeted Guinea fowl (Numida meleagris) & & 1 & & & & 1 \\
\hline Greater Kudu (Tragelaphus strepsiceros) & & & 1 & & & 1 \\
\hline African Black Duck (Anas sparsa) & & & 2 & & & 2 \\
\hline Barn Owl ( Toyto alba) & & & 1 & & & 1 \\
\hline Leopard (Panthera leo) & & & 1 & 2 & & 3 \\
\hline Cheetah (Acinonyx jubatus) & & & & 1 & & 1 \\
\hline White-tailed Mongoose (Ichneumia albicauda) & & & & 1 & & 1 \\
\hline Caracal Lynx (Felis caracal) & & & & & 1 & 1 \\
\hline Spotted Hyena (Crocuta crocuta) & & & & & 1 & 1 \\
\hline Total animals died & & & & & & 21 \\
\hline
\end{tabular}

Source: Haramaya University Zoological Garden animal status recording book.

\subsection{Occurrence of Gastrointestinal Parasites}

Out of the 22 animals (15 males and 7 females) examined in December, 16 (72.72\%) were infected with gastrointestinal parasites. In the same way, out of the 20 animals (13 males and 7 females) examined in April, 15 (75\%) were found infected. All the animals examined in December of the species kit fox, spotted hyena and Japanese rabbit were found infected. Similarly kit fox and helmeted guinea fowl had also shown 100\% parasitic infection in April. No gastrointestinal parasites were found in Lesser Kudu both in December and April (Table 2).

The high rates of parasitic infection in the zoological garden in the present study might be contributed by management problems, improper feeding and sanitary conditions as well as environmental factors. The feeding habits of the animals were considered to be the potential source of infection as animals are usually fed on leftovers from the University student's cafeteria. In the natural and free ranging environment, wild animals have wide choice of feeds which is actually free from human contacts. However, in enclosures animals are restricted of movement and prohibited access to natural feeds in the natural environment and forced to hand-feed. This condition may suppress the immune system of the animals to fight against the parasites and other disease causing agents. The possibility of cross-transmission of parasites from human beings to the zoo animals were considered to be higher. 
Table 2. Overall prevalence of gastrointestinal parasites of animals at the zoological garden of Haramaya University in December and April.

\begin{tabular}{|c|c|c|c|c|}
\hline \multirow{2}{*}{ Animal species } & \multicolumn{2}{|c|}{ Incidence of parasite infection in December } & \multicolumn{2}{|c|}{ Incidence of parasite infection in April } \\
\hline & No. examined & No. infected & No. examined & No. infected \\
\hline Hamadryas baboon (Papio hamadryas) & 9 & $7(77.78 \%)$ & 9 & $8(88.89 \%)$ \\
\hline Vervet monkey (Cercopithecus aethiops) & 2 & $1(50 \%)$ & 2 & $1(50 \%)$ \\
\hline Lions (Panthera leo) & 3 & $2(66.67 \%)$ & 3 & $1(33.33 \%)$ \\
\hline Kit fox (Vulpes macrotis) & 2 & $2(100 \%)$ & 2 & $2(100 \%)$ \\
\hline Spotted hyena (Crocuta crocuta) & 1 & $1(100 \%)$ & -(Died) & - \\
\hline Lesser kudu (Tragelaphus imberbis) & 1 & $0(0 \%)$ & 1 & $0(0 \%)$ \\
\hline Japanese white rabbit (Oryctolagus cuniculus) & 1 & $1(100 \%)$ & -(Died) & - \\
\hline Helmeted guinea fowl (Numida meleagris) & 3 & $2(66.67 \%)$ & 3 & $3(100 \%)$ \\
\hline Total & 22 & $16(72.72 \%)$ & 20 & $15(75 \%)$ \\
\hline
\end{tabular}

\subsection{Identification of Species of Gastrointestinal Parasites}

The species of gastrointestinal parasites detected in the zoological garden is shown in Table 3. A total of 9 parasite taxa were identified both in December and in April, of which 6 (66.67\%) and 3 (33.33\%) were helminthes and protozoa respectively (Table 3). Among the parasites Trichuris spp., Strongyloides spp., Entamoeba spp. were recovered from non-human primates. Other infection including Toxocara spp., Toxascaris leonine, Trichuris spp. and Isospora spp. where observed in carnivores. Passalurus ambiguous and Eimeria spp. from white Japanese rabbit and Ascaridia spp. and Eimeria oocyts from helmeted guinea fowl were the other significant gastrointestinal parasites present in the garden.

Among the helminths in the zoological garden, Trichuris spp. had the highest prevalence (46.67\%) followed by Toxocara spp. (20\%) in December. Trichuris spp. had similar position in April (46.15\%) followed by Strongyloides spp. (23.08\%). On the other hand, Eimeria spp. (60\%) were found predominant protozoan parasite in December while Entamoeba spp. (50\%) took the lead in April (Table 3). Mixed infections were noticed in some of the animals both in December (25\%) and April (20\%). Mixed cases of helminthes such as Trichuris spp. and Strongyloides spp. in Hamadryas baboons and Trichuris spp. and Toxocara spp. in kit foxes were observed in the garden. Similarly, combinations of helminths and protozoan infections including Trichuris spp. with Entamoeba spp. in Hamadryas baboons; Toxascaris leonine with Isospora spp. in lions; Passalurus ambiguus with Eimeria spp. in rabbit and Ascaridia spp. with Eimeria spp. in helmeted guinea fowl were also observed in some animals (Table 3). In agreement with this study, many previous works reported mixed infections in wild animals in captivity [7]. Otegbade and Morenikeji [26] reported that that mixed infections may consists of two or more parasites.

The present study revealed that nematodes take the entire share of infection 
Table 3. Gastrointestinal parasites (Helminths and Protozoa) detected in fecal samples of animals in captivity at Haramaya University zoological garden.

\begin{tabular}{|c|c|c|c|c|}
\hline \multirow{2}{*}{ Animal Species } & \multicolumn{2}{|c|}{$\begin{array}{l}\text { Gastrointestinal parasites observed } \\
\text { in December and their proportions }\end{array}$} & \multicolumn{2}{|c|}{$\begin{array}{l}\text { Gastrointestinal parasites observed } \\
\text { in April and their proportions }\end{array}$} \\
\hline & Helminths & Protozoa & Helminths & Protozoa \\
\hline \multirow{2}{*}{$\begin{array}{l}\text { Hamadryas baboon } \\
\text { (Papio hamadryas) }\end{array}$} & Trichuris spp. $5(71.43 \%)^{*}$ & Entamoeba spp. $1(14.29 \%)$ & Trichuris spp. $5(62.5 \%)^{\star x}$ & Entamoeba spp. $3(37.5 \%)^{\times}$ \\
\hline & Strongyloides spp. $2(28.57 \%)^{\star}$ & & Strongyloides spp. $3(37.5 \%)^{*}$ & \\
\hline $\begin{array}{l}\text { Vervet monkey } \\
\text { (Cercopithecus aethiops) }\end{array}$ & - & Entamoeba spp. 1 (100\%) & Trichuris spp. $1(100 \%)$ & - \\
\hline Lions (Panthera leo) & $\begin{array}{l}\text { Toxascaris leonine } 1(50 \%) \\
\text { Toxocara spp. } 1(50 \%)\end{array}$ & - & Toxascaris leonine $1(100 \%)^{x}$ & Isospora spp. $1(100 \%)^{\times}$ \\
\hline Kit fox (Vulpes macrotis) & $\begin{array}{l}\text { Toxocara spp. } 1(50 \%)^{*} \\
\text { Trichuris spp. } 2(100 \%)^{*}\end{array}$ & - & Toxocara spp. $2(100 \%)$ & - \\
\hline $\begin{array}{l}\text { Spotted hyena (Crocuta } \\
\text { crocuta) }\end{array}$ & Toxocara spp. 1 (100\%) & - & - & - \\
\hline $\begin{array}{l}\text { Japanese white rabbit } \\
\text { (Oryctolagus cuniculus) }\end{array}$ & Passalurus ambiguous $1(100 \%)^{x}$ & Eimeria spp. $1(100 \%)^{\times}$ & - & - \\
\hline $\begin{array}{l}\text { Helmeted guinea fowl } \\
\text { (Numida meleagris) }\end{array}$ & Ascaridia spp. $1(50 \%)^{\times}$ & Eimeria spp. $2(100 \%)^{\times}$ & Ascaridia spp. 1 (33.33\%) & Eimeria spp. $2(66.67 \%)$ \\
\hline
\end{tabular}

${ }^{*}$ Mixed infections of helminths; ${ }^{\times}$Mixed infections of helminths and protozoan parasites.

(100\%) among the helminth parasites encountered. There were no cestodes and trematode species recovered from the fecal samples which agrees with the result of Bezjian et al. [34], who reported that no parasites eggs found by sedimentation from forest baboons at Kibale National Park, Uganda. Similarly, Singh et al. [22] reported that nematodes had the highest prevalence among the helminthes recovered in captive wild animals. The high percentages of helminths compared to protozoan parasites can also be supported by the report of Varadharajan and Kandasamy [2], who found about $58 \%$ helminth parasites and $6 \%$ protozoan infections in wild animals at V.O.C. Park and Mini Zoo, Coimbatore, India.

Most of the gastrointestinal parasites observed in this study had also been reported by several authors. The occurrence of Trichuris and Strongyloides spp. in captive wild animals were reported by Opara et al. [35]. Trichuris trichuira and Entamoeba spp. in non-human primates were reported to be more prevalent [10] [15] [19] [36]. The incidence of Toxocara cati and Toxascaris leonine in Lions in the current study was supported by Okulewicz et al. [37], Pawar et al. [38], Mukarati et al., [39]. In line with the present study Engh et al. [40] reported that Toxocara canis was infecting hyena in the Masai Mara national reserve of Kenya while Luty [41] recovered it in the feces of foxes in the University zoological garden of south western Nigeria. The presence of Passalurus ambiguous and Eimeria perforans from white rabbit was also reported by Okumu et al. [42]. Several reports revealed Ascaridia spp. to be more prevalent in birds, particularly in helmeted guinea fowl [26] [43] [44]. 
Overall, the high incidences of the same species of parasites among the animals in the garden indicated that there was a share the parasites between the animals in the garden. The introduction of large numbers of visitors to the animal habitats and the closeness of humans to the animals, particularly non-human primates in the zoological gardens might have caused the exchange of parasites between humans and animals. The presence of Trichuris, Strongyloides and Toxocara spp. in high numbers in the animals in the current study may be due to the contact with human beings as these species of helminthes are more likely to be transmitted from humans to animals. The spread of gastrointestinal parasites among zoo animals by zoo keepers were reported by several authors [16] [26] [35]. Arafa et al. [45] reported that unhygienic zoo keepers can potentially transmit parasites between the animals especially when the life cycle is direct. Calvignac-Spencer et al. [46] stated that people who share the same habitat with nonhuman primates are considered as potential sources of transmission. Prevalence of zoonotic gastrointestinal parasites was reported in Papio anubis (baboon) and Cercopithecus aethiops (vervet) in Ethiopia [47]. Maske et al. [14] and Kashid et al. [9] reported that parasites can be transmitted from wild animals to domestic animals and man and vice-versa.

\subsection{Seasonal Patterns of Gastrointestinal Parasites in the Garden}

The pattern of parasitic infection in the garden was found nearly the same throughout a year. Examinations conducted on fecal samples during dry and wet seasons indicated that there were no marked differences in the infection rates of parasites. The number of animals infected in December (72.72\%) were slightly lower than the number infected in April (75\%). On the other hand, the species and number of the parasites found was almost similar both in December (dry season) and April (a wet season). This showed that the seasonal variation in parasitic infection among the zoo animals in the garden is not remarkable. The finding was in agreement with the report of Gillespie et al. [48], who reported that seasonal variation in parasite infections was minimum. This minimum variation in parasite loads between these seasons in the zoo may indicate that the animals are kept constantly in a contaminated environment with the parasites which was also stated by Atanaskova [4]. It can also be explained that in natural environments, wild animals live on large areas and have a low genetic resistance against parasitic infections because of low exposure. However, when the wild animals are kept in captivity in zoological gardens, the problem of parasitic infections can aggravate which agrees with the observation of Muoria et al. [49].

\section{Conclusion}

This paper showed that there are gastrointestinal infestations with different parasite species in the Zoological garden of Haramaya University at an overall mean rate of $73.8 \%$. Fecal analysis revealed that nematode helminthes are the most prevalent parasites in the zoo animals. There were no Cestode and Trema- 
tode species recovered from the fecal samples. Among the nematodes, Trichuris and Strongyloides and Toxocara spp. were found to be the most prevalent parasite in the zoological garden. Seasonal patterns of parasitic infection in the zoo animals were not readily apparent among the animals and the seasons of a year. The study showed that most of the gastrointestinal parasites of wild animals examined may be zoonotic and hence future studies are needed to determine risks of cross-transmission.

\section{Acknowledgements}

The authors would like to acknowledge the assistance of Mr. Beyan Abdulahi, the manager of the Zoological garden, for his help in collecting the fecal samples and Ms. Jember Abera and Mrs. Meseret Birhane for their incredible assistance in the laboratory.

\section{Conflicts of Interest}

The authors declare no conflicts of interest regarding the publication of this paper.

\section{References}

[1] Borghare, A.T., Bagde, V.P., Jaulkar, A.D., Katre, D.D., Jumde, P.D., Maske, D.K. and Bhangale, G.N. (2009) Incidence of Gasrointestinal Helminthiasis in Captive Deers at Nagpur. Veterinary World, 2, 337-338.

[2] Varadharajan, A. and Kandasamy, A. (2000) A Survey of Gastro-Intestinal Parasites of Wild Animals in Captivity in the V.O.C. Park and Mini Zoo, Coimbatore, Case report. Zoos' Print Journal, 15, 257-258. https://doi.org/10.11609/JoTT.ZPJ.15.5.257-8

[3] Parasani, H.R., Momin, R.R., Maradin, M.G. and Veer, S. (2001) A Survey of Gastrointestinal Parasites of Captive Animals at Rajkot Munipical Corporation Zoo, Rajkot, Gujarat. Zoos' Print Journal, 16, 604-606. https://doi.org/10.11609/JoTT.ZPJ.16.10.604-6

[4] Atanaskova, E., Z. Kochevski, Stefanovska, J. and Nikolovski, G. (2011) Endoparasites in Wild Animals at the Zoological Garden in Skopje, Macedonia. Journal of Threatened Taxa, 3, 1955-1958. https://doi.org/10.11609/JoTT.o2440.1955-8

[5] Varadharajan, A. and Sbramanian, H. (2003) Influence of Age on the Prevalence of Parasitic Infections among Wild Mammals in Thrissur Zoo, Thrissur Kerala. Zoos Print Journal, 18, 1065-1066. https://doi.org/10.11609/JoTT.ZPJ.18.4.1065-6

[6] Goossensa, E., Dornya, P., Boomkerd, J., Vercammen, F. and Vercruysse (2005) A 12-Month Survey of the Gastro-Intestinal Helminths of Antelopes, Gazelles and Giraffes Kept at Two Zoos in Belgium. Veterinary Parasitology, 127, 303-312. https://doi.org/10.1016/j.vetpar.2004.10.013

[7] Singh, P., Gupta, M.P., Singla, L.D., Sharma, S., Sandhu, B.S. and Sharma, D.R. (2006) Parasitic Infections in Wild Herbivores in the Mahendra Choudhuryzoological Park, Chhatbir, Punjabp. Zoos' Print Journal, 21, 2459-2461. https://doi.org/10.11609/JoTT.ZPJ.1519.2459-61

[8] Chakraborty, A., Gogoi, A.R. and Choudhary, B. (1994) Prevalence of Parasitic Infection in Captive Wild Herbivores in a Zoo in Assam, India. Indian Journal of 
Animal Science, 9, 149-152.

[9] Kashid, K.P., Shrikhande, G.B. and Bojne, G.R. (2003) Incidence of Gastro-Intestinal Helminths Captive Wild Animals at Different Locations. Zoos' Print Journal, 18, 1053-1054. https://doi.org/10.11609/JoTT.ZPJ.18.3.1053-4

[10] Adetunji, V.E. (2014) Prevalence of Gastro-Intestinal Parasites in Primates and Their Keepers from Two Zoological Gardens in Ibadan, Nigeria. Sokoto Journal of Veterinary Science, 12, 25-30.

[11] Papini, R., Girivetto, M., Marangi, M., Mancianti, F. and Giangaspero, A. (2012) Endoparasite Infections in Pet and Zoo Birds in Italy. The Scientific World Journal, 1, 1-9. https://doi.org/10.1100/2012/253127

[12] Simpson, V.R. (2002) Wild Animals as Reservoirs of Infectious Diseases in the UK. The Veterinary Journal, 163, 128-146. https://doi.org/10.1053/tvjl.2001.0662

[13] Bohm, M., White, P.C.L., Chambers, J., Smith, L. and Hutchings, M.R. (2007) Wild Deer as a Source of Infection for Livestock and Humans in the UK. The Veterinary Journal, 174, 260-276. https://doi.org/10.1016/j.tvjl.2006.11.003

[14] Maske, D.K., Bhilegaonkar, N.C. and Sardey, M.R. (1990) Helminth Parasites in Zoo Animals of Maharajbagh, Nagpur, Maharashtra State. Indian Journal of Animal Science, 5, 277-278.

[15] Munene, E., Otsyula, M., Mbaabu, W.T., Mutahi, S.M.K., Murinki, S.M.K. and Muchemi, G.M. (1998) Helminthes and Protozoan Gastrointestinal Tract Parasites in Captive and Wild-Trapped African Non-Human Primates. Veterinary Parasitology, 78, 195-201. https://doi.org/10.1016/S0304-4017(98)00143-5

[16] Levecke, B., Dorny, P., Geurden, T., Vercammen, F. and Vercruysse, J. (2007) Gastrointestinal Protozoa in Non-Human Primates of Four Zoological Gardens in Belgium. Veterinary Parasitology, 148, 236-246. https://doi.org/10.1016/j.vetpar.2007.06.020

[17] Mbaya, A.W. and Udendeye, U.J. (2011) Gastrointestinal Parasites of Captive and Free-Roaming Primates at the Afi Mountain Primate Conservation Area Calabar, Nigeria and Their Zoonotic Implication. Pakistan Journal of Biological Science, 14, 707-714. https://doi.org/10.3923/pjbs.2011.709.714

[18] Bichitra, G.N., Saidul, I. and Apurba, C. (2012) Prevalence of Parasitic Infection in Captive Non Human Primates of Assam State Zoo, India. Veterinary World, 5, 614-616. https://doi.org/10.5455/vetworld.2012.614-616

[19] Dawet, A., Yakubu, D.P. and Butu H.M. (2013) Survey of Gastrointestinal Parasites of Nonhuman Primates in Jos Zoological Garden. Journal of Primatology, 2, 1-3.

[20] Nashiruddullah, N. and Chakraborty, A. (2001) Parasites of Captive Wild Carnivores of Assam State Zoo. Intas Polivet, 2, 173-181.

[21] Acharjyo, L.N. (2004) Helminthiasis in Captive Wild Carnivores and Its Control in India. Review, Zoos' Print Journal, 19, 1540-1543. https://doi.org/10.11609/JoTT.ZPJ.1001.1540-3

[22] Singh, P., Gupta, M.P., Singla, L.D., Singh, N. and Sharma, D.R. (2006a) Prevalence and Chemotherapy of Gastrointestinal Helminthic Infections in Wild Carnivores in Mahedra Choudhury Zoological Park, Punjab. Journal of Veterinary Parasitology, 20, 17-23.

[23] Rahman, S.M., Dey, A.R., Kundu, U.K. and Begum, N. (2014) Investigation of Gastrointestinal Parasites of Herbivores at Dhaka National Zoological Garden of Bangladesh. Journal of Bangladesh Agricultural University, 12, 79-85. https://doi.org/10.3329/jbau.v12i1.21245 
[24] Patel, P.V., Patel, A.I., Sahu, R.K. and Vyas, R. (2000) Prevalence of Gastrointestinal Parasites in Captive Birds of Gujarat Zoos. Zoos Print Journal, 15, 295-296. https://doi.org/10.11609/JoTT.ZPJ.15.7.295-6

[25] Parsani, H.R., Momin, R.R., Sahu, R.K. and Patel, B.G. (2003) Prevalence of Gastrointestinal Parasites in Captive Birds at Kamla Nehru Zoological Garden, Kankaria Zoo, Ahmedabad, Gujarat. Zoos Print Journal, 1, 987-992. https://doi.org/10.11609/JoTT.ZPJ.18.1.987-92

[26] Otegbade, A.C. and Morenikeji, O.A. (2014) Gastrointestinal Parasites of Birds in Zoological Gardens in South-West Nigeria. Tropical Biomedicine, 31, 54-62.

[27] Wolf, D., Vrhovec, M.G., Failing, K., Rossier, C., Hermosilla, C. and Pantchev, N. (2014) Diagnosis of Gastrointestinal Parasites in Reptiles: Comparison of Two Coprological Methods. Acta Veterinaria Scandinavica, 56, 44 https://doi.org/10.1186/s13028-014-0044-4

[28] Soulsby, E.J.L. (1982) Helminths, Anthropods and Protozoa of Domesticated Animals. 7th Edition, Bailliere Tindall, London, 66-71.

[29] Roepstorff, A. and Nansen, P. (1998) Epidemiology, Diagnosis and Control of Helminth Parasites of Swine, FAO Animal Health Manual. Danish Centre for Experimental Parasitology, the Royal Veterinary and Agricultural University, Copenhagen, 35-68.

[30] Hansen, J. and Perry, B. (1994) The Epidemiology, Diagnosis and Control of Helmiths Parasites of Ruminants. International Laboratory for Research on Animal Disease (ILRAD), Nairobi, 158-168.

[31] Van Wyk, J.A. and Mayhew, E. (2013) Morphological Identification of Parasitic Nematode Infective Larvae of Small Ruminants and Cattle: A Practical Lab Guide. Onderstepoort Journal of Veterinary Research, 80, 1-14. https://doi.org/10.4102/ojvr.v80i1.539

[32] Diereweld, E.S. (1997) Captive Wild Animal Nutrition: A Historical Perspective. Symposium on "Nutrition of Wild and Captive Wild Animals". Proceedings of the Nutrition Society, 56, 989-999. https://doi.org/10.1079/PNS19970104

[33] Young, R.J. (1997) The Importance of Food Presentation for Animal Welfare and Conservation. Proceedings of the Nutrition Society, 56, 1095-1104. https://doi.org/10.1079/PNS19970113

[34] Bezjian, M., Gillespie, T.R., Chapman, C.A. and Greiner, E.C. (2008) Coprologic Evidence of Gastrointestinal Helminthes of Forest Baboons, Papio Anubis, in Kibale National Park, Uganda. Journal of Wildlife Disease, 44, 878-887. https://doi.org/10.7589/0090-3558-44.4.878

[35] Opara, M.N., Osuji, C.T. and Opara, J.A. (2010) Gastrointestinal Parasitism in Captive Animals at the Zoological Garden, Nekede Owerri, Southeast Nigeria. Report and Opinion, 2, 5.

[36] Egbetade, A., Akinkuotu, O., Jayeola, O., Niniola, A., Emmanuel, N., Olugbogi, E. and Onadeko, S. (2014) Gastrointestinal Helminths of Resident Wildlife at the Federal University of Agriculture Zoological Park, Abeokuta. Sokoto Journal of Veterinary Sciences, 12, 26-31. https://doi.org/10.4314/sokjvs.v12i3.5

[37] Okulewicz, A., Perec-Matysiak, A., Buńkowska, K. and Hildebrand, J. (2012) Toxocara canis, Toxocara cati and Toxascaris leonina in Wild and Domestic Carnivores. Helminthologia, 49, 3-10. https://doi.org/10.2478/s11687-012-0001-6

[38] Pawar, R.M., Lakshmikantan, U., Hasan, S. Poornachandar, A. and Shivaji, S. (2012) Detection and Molecular Characterization of Ascarid Nematode Infection (Toxascaris leonina and Toxocara cati in in captive Asiatic Lions (Panthera leo persica). Ac- 
ta Parasitologica, 57, 67-73. https://doi.org/10.2478/s11686-012-0012-y

[39] Mukarati, N.L., Vassilev, G.D., Tagwireyi, W.M. and Tavengwa, M. (2013) Occurrence, Prevalence and Intensity of Internal Parasite Infections of African Lions (Panthera leo) in Enclosures at a Recreation Park in Zimbabwe. Journal of Zoo and Wildlife Medicine, 44, 686-693. https://doi.org/10.1638/2012-0273R.1

[40] Engh, A.L., Nelson, K.G., Peebles, R., Hernandez, A.D., Hubbard, K.K. and Holekamp, K.E. (2003) Coprologic Survey of Parasites of Spotted Hyenas (Crocuta crocuta) in the Masai Mara National Reserve, Kenya. Journal of Wildlife Diseases, 39, 224-227. https://doi.org/10.7589/0090-3558-39.1.224

[41] Luty, T. (2001) Prevalence of Species of Toxocara in Dogs, Cats and Red Foxes from the Poznan Region, Poland. Journal of Helminthology, 75, 153-156.

[42] Okumu, P.O., Gathumbi, P.K., Karanja, D.N., Mande, J.D., Wanyoike, M.M., Gachuiri, C.K., Kiarie, N., Mwanza, R.N. and Borter, D.K. (2014) Prevalence, Pathology and Risk Factors for Coccidiosis in Domestic Rabbits (Oryctolagus cuniculus) in Selected Regions in Kenya. Veterinary Quarterly, 34, 205-210. https://doi.org/10.1080/01652176.2014.978044

[43] Biu, A.A., Rabo, J.S., Dawurung, J.S. and Lagu, A.A. (2012) Prevalence of Nematodes of Domesticated Guinea Fowl in Maiduguri, Nigeria. New York Science Journal, 5, 6-8.

[44] Singh, K. and Muhammed, A. (2014) Parasitic Nematode Infections in Guinea Fowl (Numidia meleagris) in Sokoto, Nigeria. World Journal of Environmental Biosciences, 5, 35-36.

[45] Arafa, W.M., Lilian, N., Mahrous, S.M., Aboelhadid, A. and Abdel-Ghany, E. (2013) Investigation of Enteric Parasites of Zoo Animals and Zookeepers in Beni-Suef Governorate, Egypt. Journal of Veterinary Medical Research, 22, 121-125. https://doi.org/10.21608/jvmr.2013.77693

[46] Calvignac-Spencer, S., Leendertz, S.A.J., Gillespie, T.R. and Leendertz, F.H. (2012) Wild Great Apes as Sentinels and Sources of Infectious Disease. Clinical Microbiology and Infection, 18, 521-527. https://doi.org/10.1111/j.1469-0691.2012.03816.x

[47] Legesse, M. and Erko, B. (2004) Zoonotic Intestinal Parasites in Papio anubis (Baboon) and Cercopithecus aethiops (Vervet) from four Localities in Ethiopia. Acta Tropica, 90, 231-236. https://doi.org/10.1016/j.actatropica.2003.12.003

[48] Gillespie, R.T., Greiner, E.C. and Chapman, C.A. (2004) Gastrointestinal Parasites of Guenons of Western Uganda. Journal of Parasitology, 90, 1356-1360. https://doi.org/10.1645/GE-311R

[49] Muoria, P.K., Muruthi, P., Rubenstein, D., Oguge, N.O. and Munene, E. (2005) Cross Sectional Survey of Gastro-Intestinal Parasites of Grevy's Zebras in Southern Samburu, Kenya. African Journal of Ecology, 43, 392-395.

https://doi.org/10.1111/j.1365-2028.2005.00588.x 